\title{
Health Promotion
}

National Cancer Institute

\section{Source}

National Cancer Institute. Health Promotion. NCI Thesaurus. Code C15243.

The realization that individual behavior plays a key role in health and disease prevention.

Health promotion encourages individuals to adopt and maintain healthy behaviors (e.g., good eating habits and regular physical exercise) and modify unhealthy behaviors (e.g., quitting smoking) to foster healing and reduce the risks of major chronic diseases. 